ZOOLOGIA 32 (1): 47-52, February 2015

http://dx.doi.org/10.1590/S1984-46702015000100007

\title{
A new genus and new species of spittlebug (Hemiptera: Cercopidae: Ischnorhininae) from Southern Brazil
}

\author{
Andressa Paladini' \& Rodney Ramiro Cavichioli ${ }^{1,2}$
}

\author{
${ }^{1}$ Departamento de Zoologia, Universidade Federal do Paraná. Caixa Postal 19020, 81531-980 Curitiba, PR, Brazil. \\ E-mail: andri_bio@yahoo.com.br \\ ${ }^{2}$ Corresponding author. E-mail: cavich@ufpr.br
}

\begin{abstract}
A new genus of spittlebug is described to include Gervasiella oakenshieldi sp. nov. (holotype male from Brazil, state of Paraná, municipality of Piraquara, Mananciais da Serra at $25^{\circ} 29^{\prime} 46^{\prime \prime S}, 48^{\circ} 58^{\prime} 54^{\prime \prime} \mathrm{W}, 1000 \mathrm{~m}$ a.s.I., 15.XI.2008, P.C. Grossi leg., deposited in DZUP). In addition, Aeneolamia bucca Paladini \& Cavichioli, 2013 is transferred to Gervasiella gen. nov. based on the results of a cladistic analysis. Gervasiella gen. nov. can be distinguished from the other cercopid genera by the following: postclypeus inflated with upper portion black and basal one yellowish; color of tylus distinct from color of head and rostrum, barely reaching mesocoxae. Gervasiella oakenshieldi sp. nov. is diagnosed by having the head black with tylus white, postclypeus in profile inflated and convex with a prominent longitudinal carina; tegmina black with two elongate white maculae near costal margin, one on anterior third and the other on posterior third.
\end{abstract}

KEY WORDS. Auchenorrhyncha; Neotropical Region; phylogeny; taxonomy.

Insects belonging to Cercopidae are known as spittlebugs due to the bubble nest produced by the nymphs. This family forms a large group of xylem feeding insects with approximately 1500 worldwide species included in 150 genera. Most species are distributed in the tropical and subtropical regions. Adults feed on leaves or stems of a wide variety of plants, nymphs can feed on roots and in some cases they complete their development above the ground (Carvalho \& Weвв 2005).

The Neotropical genera of Cercopidae have been usually defined by characters of the head and pronotum, and by the number of spines on the hind leg. The same set of characters also form the basis of the tribal classification proposed by FENNAH (1968).

An ongoing study on Neotropical cercopids has revealed a new genus of Ischnorhininae. The new genus and the new species are described and illustrated. Also, we propose a new combination: Aeneolamia bucca Paladini \& Cavichioli, 2013 is transferred to Gervasiella gen. nov. The species of Gervasiella gen. nov. are distinguished based on a comparative diagnosis.

\section{MATERIAL AND METHODS}

The specimens studied are deposited in the Coleção Entomológica Padre Jesus Santiago Moure, Departamento de Zoologia, Universidade Federal do Paraná, Curitiba, Paraná, Brazil (DZUP). Morphological terminology follows FenNAH (1968) and Paladini \& CRYAN (2012). Techniques for preparation of genital structures follow Oman (1949). The dissected parts were stored in micro vials with glycerin. Photographs were obtained with a Leica DFC-550 digital camera attached to the stereomicroscope (Leica MZ16) and captured with the software IM50 (Image Manager; Leica Microsystems Imaging Solutions Ltd, Cambridge, UK), after montage using Auto-Montage Syncroscopy of Taxonline (Rede Paranaense de Coleções). Illustrations were made with the aid of a camera lucida and the final art were finalized using vectors with the software CorelDraw version X5.

Terminal taxa. Besides the Neotropical cercopids present in the matrix analyzed by PALADINI et al. (2015) two species of Gervasiella gen. nov. were also included, to test the validity of the new genus proposed here.

Characters were coded to include most of the morphological variation of the external morphology of the adult, and male and female genitalia. We included and reanalyzed 108 characters from the cladistics analysis of PALADINI et al. (2015), and added two characters totaling 110 characters. Each character was considered a hypothesis of grouping. Primary homologies were proposed by similarity or topological correspondence (DE PINNA 1991). The contingent coding was used when novel features appeared and evolved, and this feature shows variation (SERENO 2007). Multistate characters were treated as unordered (nonadditive) (FITCH 1971). Character state polarity was determined by outgroup rooting (NIXON \& CARPENTER 1993). Missing data were coded as '?' and nonapplicable characters were coded as ' - '. The data matrix was built using Winclada v1.00.08 (Nixon 2002).

2015 | Sociedade Brasileira de Zoologia | www.sbzoologia.org.br | www.scielo.br/zool All content of the journal, except where identified, is licensed under a Creative Commons attribution-type BY-NC. 
Analyses were performed using two character weighting schemes: equal weight and implied weight. Analyses were conducted using TNT version 1.1 (Goloboff et al. 2008) using Traditional Search basing the heuristic search strategies on RAS + TBR (random addition sequences plus swap by tree bisection and reconnection), with 1,000 replications with 100 trees saved per replication. The choice for the best constant of concavity (K) values range for the data followed the methodology of Paladini et al. (2015). The best $\mathrm{K}$ range for the data matrix presented here was 8-13. Branch support was calculated using the relative Bremer support (Goloboff \& FarRIs 2001). Nonparametric Bootstrap support values were computed running 1000 bootstrap pseudoreplicates (Felsenstein 1985).

\section{TAXONOMY}

\section{Gervasiella gen. nov.}

Type species. Gervasiella oakenshieldi sp. nov. by original designation.

Diagnosis. Gervasiella gen. nov. can be distinguished from all other cercopids genera by the following combination of characters: 1) postclypeus inflated with upper portion black and basal one yellowish; 2) tylus with a distinct color from the head; 3) rostrum barely reaching mesocoxae; 4) subgenital plates shorter than pygofer, in ventral view quadrangular with apex truncate; 5) paramere long and slender, apex rounded, a unique subapical spine quadrangular; 6) paramere's spines located upon a lateral concavity similar to a hole; 7) aedeagus slender with quandrangular and wide base, one pair of dorsal processes long and slender turned upward.

Description. Head triangular with two deep impressions on the vertex near the median line; tylus quadrangular; ocelli near to each other than the compound eyes. Antennae with pedicel visible in dorsal view, flagellum normal in length, with ovoid basal body and an arista almost as long as pedicel; postclypeus inflated, convex in profile with a well-marked longitudinal carina; rostrum barely reaching mesocoxae. Pronotum hexagonal, surface smooth; anterior and lateral anterior margins straight; posterior and lateroposterior margins slightly sinuated; tegmina long and slender. Hindwings with $\mathrm{Cu} 1$ not thickened at base. Hind tibiae with two lateral spines and a row of apical spines; hind basitarsus with apical spines distributed in two irregular rows. Pygofer with one process between anal tube and subgenital plate in lateral view; subgenital plate quandrangular in ventral view. Aedeagus long, slender with one pair of dorsal processes; parameres slender, dorsal margin with two processes, one subapical spine quadrangular and sclerotized. First valvulae of ovipositor with two processes near the base; second valvulae with dorsal margin smooth.

Etymology. The genus is named in honor of Prof. Dr. Gervásio Silva Carvalho, a specialist of Neotropical cercopids, in recognition of his expertise and several contributions to the taxonomy of the group.
Remarks. Based on the tree resulting from the cladistics analysis (Figs. 12 and 13), Gervasiella gen. nov. is sister group of the clade including Prosapia Fennah, 1949, Aeneolamia Fennah, 1949 and Isozulia Fennah, 1953. In these genera the aedeagus presents a long and slender dorsal process inserted medially. Gervasiella gen. nov. is supported by two synapomorphies: paramere with a concavity under the spine (Figs. 14 and 15) and aedeagus base quadrangular (Figs. 16 and 17).

\section{Gervasiella oakenshieldi sp. nov.}

Figs. 1-11, 19

Measurements. Length, male $6.8 \mathrm{~mm}$; females 6.7-7.8 $\mathrm{mm}$.

Diagnosis. Head black with tylus white, postclypeus in profile, inflated and convex with a prominent longitudinal carina; tegmina black with two elongate white maculae near the costal margin, one on the anterior third and the other on the posterior third.

Description. Head triangular black; rostrum yellowish with the third segment black; compound eyes black, rounded, arranged transversely; vertex smooth, rectangular, with a prominent median carina; ocelli reddish near to each other than to compound eyes; tylus white, smooth, quadrangular, lacking a median carina; antennae black, pedicel scarcely setose, basal body of flagellum ovoid with an arista almost as long as the pedicel; postclypeus inflated, convex in profile with a wide longitudinal carina, lateral grooves slightly marked, apical portion black and two basal thirds yellowish. Thorax black; pronotum black, flattened, hexagonal, lacking median carina, anterior margin straight, lateral-anterior margins straight, lateral-posterior margin slightly sinuous, posterior margin with a light groove; scutellum black, with a slight central concavity and transversal grooves. Tegmina black with two white maculae: the first one elongated, located near the costal margin, extending from its base until the median third of the tegmina; the second one rounded located between the median and apical third; apical plexus of vein poorly developed; hindwings hyaline with brown venation; vein $\mathrm{Cu} 1$ not thickened at base; legs brownish; metathoracic tibia with two lateral spines (basal spine equal in size to spines in apical crown; apical spine larger than spines in apical crown); apical crown of spines on tibia consisting of two rows; basitarsus with one row of spines covered by sparse setae; subungueal process absent.

Male genitalia. Pygofer with one quadrangular process between the anal tube and subgenital plates; subgenital plates short, quadrangular with a rounded apex, dorsal margin produced in a rectangular process (Fig. 3); parameres long and slender with a quandrangular sclerotized spine turned backwards located over a concavity on the external side, dorsal margin with a finger like process turned to the inner side (Figs. 7 and 8); aedeagus cylindrical with a pair of dorsal processes long and slender turned upward, aedeagus base quadrangular and wide, apex quadrangular (Figs. 5 and 6). 

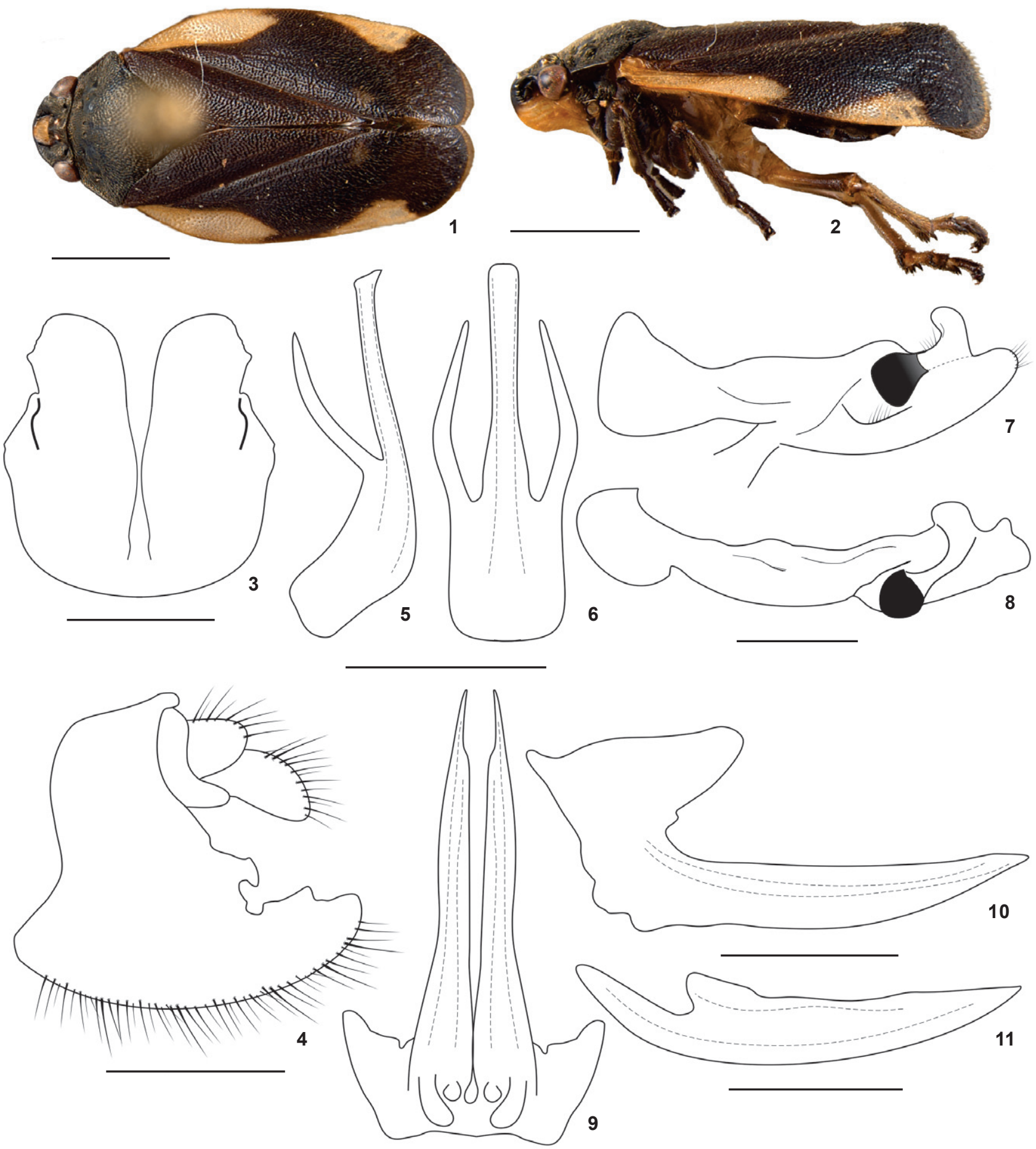

Figures 1-11. Gervasiella oakenshieldi sp. nov.: (1-2, 9-11) female paratype, (3-8) male holotype: (1) habitus, dorsal view; (2) habitus, lateral view; (3) subgenital plates and pygofer, ventral view; (4) pygofer and subgenital plates, lateral view; (5) aedeagus, lateral view; (6) aedeagus, dorsal view; (7) paramere, lateral view; (8) paramere, dorsal view; (9) first valvulae of ovipositor, ventral view; (10) first valvulae of ovipositor, lateral view; (11) second valvulae of ovipositor, lateral view. Scale bars: 1-2 = $2 \mathrm{~mm}, 3,4,9-11=0.5 \mathrm{~mm}, 5-8=0.25 \mathrm{~mm}$. 

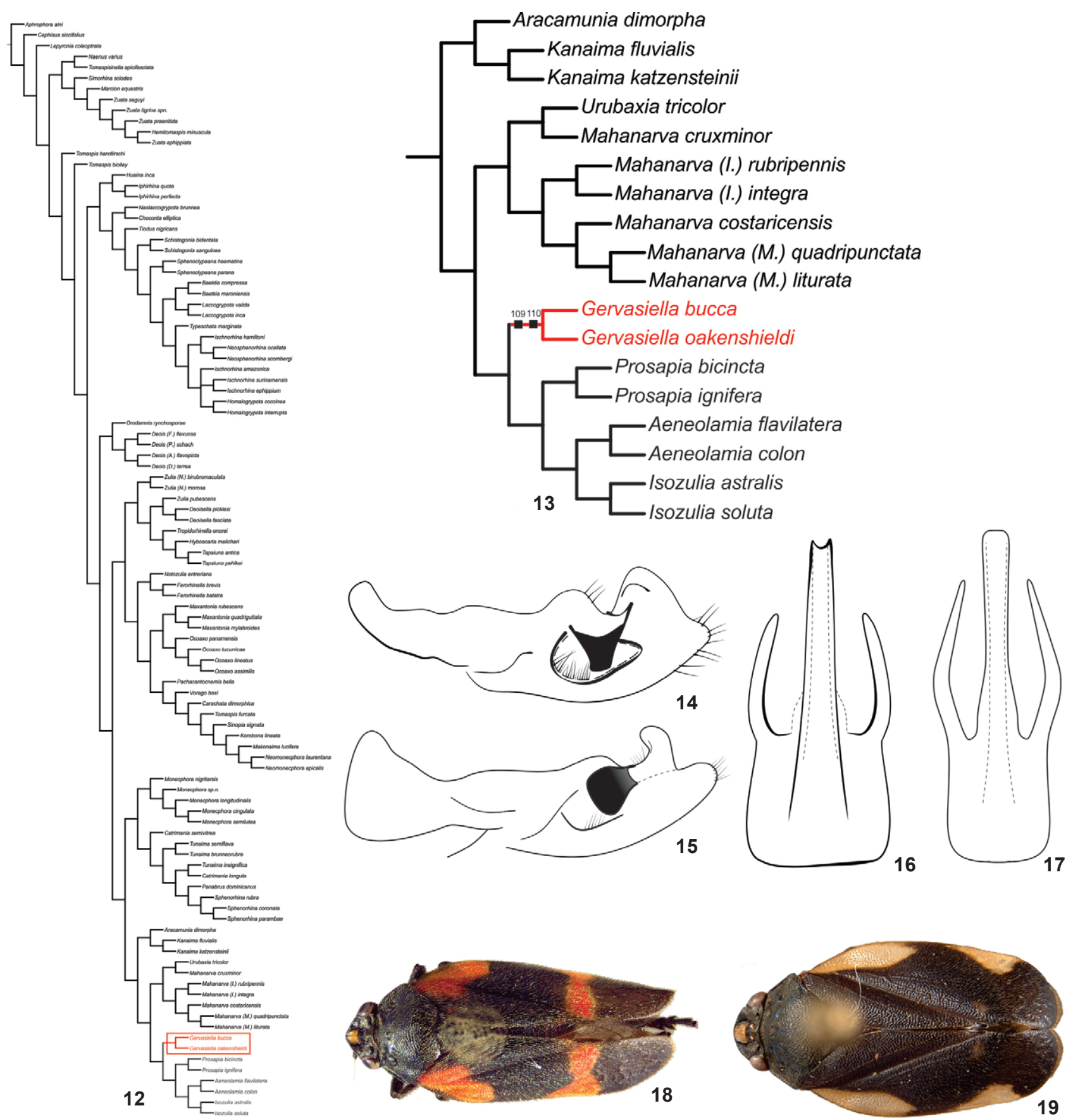

Figures 12-19. Phylogenetic relationships of Ischnorhininae and diagnostic characters of Gervasiella gen. nov.: (12) unique most parsimonious tree resulting from the analysis of morphological data with the implied weighting scheme using the optimal constant of concavity interval of K8-12, highlighting the position of Gervasiella gen. nov.; (13) clade including Gervasiella gen. nov.; (14) Gervasiella bucca comb. nov. paramere in lateral view; (15) Gervasiella oakenshieldi sp. nov. parameres in lateral view; (16) Gervasiella bucca comb nov. aedeagus in dorsal view; (17) Gervasiella oakenshieldi sp. nov. aedeagus in dorsal view; (18) Gervasiella bucca dorsal habitus; (19) Gervasiella oakenshieldi sp. nov. dorsal habitus. 
Female. First valvulae of ovipositor long and slender with acute apex and two basal process poorly developed, rounded, directed ventrally (Figs. 9 and10); second valvulae long and slender, dorsal margin smooth (Fig. 11), third valvulae short and wide, with long setae ventrally.

Etymology. Noun in genitive singular after to a fictional character surname of the novel The Hobbit, Thorin Oakenshield; in honor to J.R.R Tolkien an English writer known as the author of classic fantasy books.

Remarks. Gervasiella oakenshieldi sp. nov. (Figs. 1-2 and 19) superficially resembles Gervasiella bucca comb. nov. (Fig. 18) in having the same color pattern but the paramere is slender, with the concavity under the spine less pronounced (Fig. 15).

Examined material. Holotype male from BraziL, Paraná: Piraquara (Mananciais da Serra 2529'46"S, 4858'54"W, 1000 $\mathrm{m}$ a.s.1., 15.XI.2008), P.C. Grossi leg. Paratypes: 1 female same data as holotype; 1 female, same locality as holotype but 25.III.2012, light trap; 1 female same locality as holotype but flight interception [trap], XI.2007, P.C. Grossi \& D. Parizotto leg. All deposited in DZUP.

\section{Gervasiella bucca}

(Paladini \& Cavichioli, 2013) comb. nov.

Figs. 14, 16, 18

Aeneolamia bucca Paladini \& Cavichioli, 2013: 353.

Diagnosis. General coloration black; tegmina with basal red macula and one apical red stripe; Pygofer short with finger-like process between anal tube and subgenital plates; aedeagus with one pair of dorsal, slender processes directed upward.

Remarks. Gervasiella bucca was originally described in Aeneolamia due to a superficial resemblance in the morphology of the male genitalia, although other features indicated that those species were not congeneric. Subsequently, Gervasiella gen. nov. was erected to accommodate G. bucca and the newly described G. oakenshieldi sp. nov., based on the examination of additional specimens from Southern Brazil (from the municipality of Piraquara, Paraná State). Diagnostic traits of this genus were previously mentioned in the generic diagnosis. These features were later recovered as synapomorphies validating the monophyly of Gervasiella gen. nov., as inferred in our morphology-based phylogenetic analysis of Ischnorhininae that included both G. bucca and G. oakenshieldi sp. nov.

\section{CLADISTIC ANALYSIS}

List of new characters. The complete list of characters can be found in PALAdinI et al. (2015) and the full data matrix is available in Appendix $\mathrm{S}^{1}$. The two new characters included in the analysis are: Male genitalia: (109) Paramere, lateral view, concavity under the main spine: (0) absent; (1) present; and (110) Aedeagus, shape of base in dorsal view: (0) rectangular; (1) quadrangular. The data matrix included 102 taxa and 110 characters (Appendix $\mathrm{S}^{1}{ }^{1}$ ). The equal weights analysis produced 30 equally parsimonious trees (length $=1061$ steps, $\mathrm{CI}=14$, RI =61). The strict consensus cladogram had 59 collapsed nodes. The relationships among genera were poorly resolved. In the analysis with implied weighting scheme the best $\mathrm{K}$ range for the data matrix presented here was $8-12$; this range was chosen based on PALADini et al. (2015). The five trees obtained with the best $\mathrm{K}$ range were had the same topology,(Fig. 12) which will be used as the hypothesis to infer the phylogenetic relationship and monophyly of Gervasiella gen. nov. The topology obtained in the present analysis is similar to that of PALADINI et al. (2015) except for the inclusion of the new genus. Only unambiguous characters were optimized in the resultant cladogram.

The main goal of this cladistics analysis was to evaluate and to support the description of a new genus. The clade Gervasiella gen. nov. (Fig. 13) has a relative Bremer support of 71 and a Bootstrap support of 99 . The genus is supported by two synapomorphies: paramere with a concavity located under the main spine $\left(109_{1}\right)$ and aedeagus with a quadrangular base $\left(110_{1}\right)$. and 10 a homoplasious character-state transformations: vertex shape narrow $\left(3_{0}\right)$; antennae with basal body of flagellum ovoid $\left(6_{1}\right)$; posterior margin of pronotum slightly grooved $\left(31_{0}\right)$; tegmina venation almost indistinct $\left(37_{2}\right)$; tegmina with apical plexus of veins reduced $\left(40_{1}\right)$; basitarsus of the posterior leg with two rows of spines $\left(47_{1}\right)$; subgenital plates short compared to pygofer $\left(53_{0}\right)$; apex of subgenital plates truncated $\left(50_{2}\right)$; spine of paramere oriented vertically $\left(69_{1}\right)$; ovipositor with two basal processes $\left(103_{1}\right)$.

Gervasiella gen. nov. is included in the clade Tomaspidini and is sister group to Prosapia, Aeneolamia, and Isozulia.

\section{ACKNOWLEDGEMENTS}

We thank Paschoal C. Grossi (UFRPE) and Daniele Parizzoto for collecting and generously providing specimens; Olivia Envangelista (MZUSP) for her valuable suggestions; the anonymous reviewers and associate editor for their constructive comments and significant improvement on an earlier version of this manuscript. This work was supported by a CNPq postdoctoral grant (process 150163/2013-4) to the senior author. This research is also partially funded by the advisor's grant (RRC) from PROTAX/CNPq (processes 561298/2010-6 and $303127 / 2010-4)$. This paper is the contribution number 1917 of the Departamento de Zoologia, Universidade Federal do Paraná.

\footnotetext{
${ }^{1}$ Available as Online Supplementary Material accessed with the online version of the manuscript at http://www.scielo.br/zool
} 


\section{LITERATURE CITED}

Carvalho GS, Webb MD (2005) Cercopid Spittlebugs of the New World (Hemiptera, Auchenorrhyncha, Cercopidae). Sofia, Pensoft, 271p.

DE PInNa MCC (1991) Concepts and tests of homology in the cladistics paradigm. Cladistics 7(4): 367-394.

Fennah RG (1968) Revisionary notes on the new world genera of cercopid froghoppers (Homoptera, Cercopoidea). Bulletin of Entomological Research 58: 165-190.

Felsenstein J (1985) Confidence limits on phylogenies: an approach using the bootstrap. Evolution 39: 783-791.

Fiтch WN (1971) Toward defining the course of evolution, minimum change for a specified tree topology. Systematic Zoology 20: 406-416.

Goloboff PA, JS Farris (2001) Methods for quick consensus estimation. Cladistic 17(1): S26-S34. doi: 10.1111/j.10960031.2001.tb00102.x

Goloboff PA, Farris JS, Nixon KC (2008) TNT, a free program for phylogenetic analysis. Cladistics 24(5): 774-786. doi: 10.1111/j.1096-0031.2008.00217.x
Nixon KC (2002) Winclada. New York, Published by the Author, v. 1.00.08.

Nixon KC, Carpenter JM (1993) On outgroups. Cladistics 9(4): 413-426. doi: 10.1111/j.1096-0031.1993.tb00234.x

OMAn PW (1949) The Nearctic leafhoppers (Homoptera: Cicadellidae). A generic classification and check list. Memoirs of the Entomological Society of Washington 3: $1-253$.

Paladini A, Cavichioli RR (2013) A new species of Aeneolamia (Hemiptera: Cercopidae: Tomaspidinae) from the Neotropical Region. Zoologia 30(3): 353-355. doi: 10.1590/S198446702013000300016

Paladini A, Cryan JR (2012) Nine new species of Neotropical spittlebugs. Zootaxa 3519: 53-68.

Paladini A, TakiYa DM, Cavichioli RR, Carvalho GS (2015) Phylogeny and biogeography of Neotropical spittlebugs (Hemiptera: Cercopidae: Ischnorhininae): revised tribal classification based on morphological data. Systematic Entomology 40(1): 82-108. doi: 10.1111/syen.12091

SERENO PC (2007) Logical basis for morphological characters in phylogenetics. Cladistics 23(6): 565-587.

Submitted: 29 September 2014

Received in revised form: 21 January 2015

Accepted: 5 February 2015

Editorial responsibility: Ângelo Parise Pinto 